\title{
Development of a Virtual Journal Club in Anatomy: a Responsive Pandemic Pedagogy
}

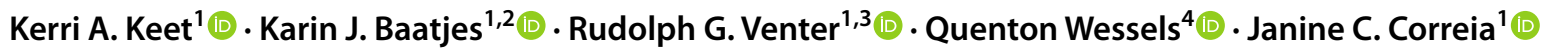

Accepted: 20 May 2021 / Published online: 2 June 2021

(c) International Association of Medical Science Educators 2021

\begin{abstract}
The COVID-19 pandemic forced changes to online teaching worldwide. The Clinical Anatomy journal club (JC) is key in the Bachelor of Science Honours (BScHons) programme and aims to improve scientific appraisal and communication abilities in anatomical research. An online JC through synchronous contact between members was deemed fitting as it could bridge the newly enforced geographical limitations due to the national lockdown in South Africa. Although common in clinical specialties, there are no published reports of anatomy themed online JCs. This project aimed to develop, implement, and appraise a synchronous virtual JC for Clinical Anatomy during the COVID-19 South African lockdown. A qualitative exploratory study design within an interpretive/constructivist paradigm was followed and aimed to explore students' perceptions of a virtual anatomy JC during the lockdown. The study was conducted at a South African institution, within the BScHons programme, and all enrolled students were invited to participate. Upon receipt of informed consent, an anonymous questionnaire was administered via Moodle for the BScHons students. The responses were analysed by thematic analysis, codes were developed, and themes were generated. Two main themes were generated from the results: the first related to the virtual format of the JC and the second focused on the content and topics covered during the JC sessions. The Clinical Anatomy staff and students adapted rapidly to the virtual JC and formed a community of practice. The benefits of teaching and learning within $\mathrm{JC}$ were maintained during the virtual format. It is envisioned that the JC will continue in a hybrid format (face-to-face and virtual) in future academic years.
\end{abstract}

Keywords Virtual journal club · Anatomical education · COVID-19 · Pandemic · Online learning

\section{Introduction}

This research was presented at the Scholarship of Teaching and Learning Conference, 4 November 2020.

Kerri A. Keet

kkeet@sun.ac.za

1 Division of Clinical Anatomy, Department of Biomedical Sciences, Faculty of Medicine and Health Sciences, Stellenbosch University, Cape Town 7550, South Africa

2 Division of Surgery, Department of Surgical Sciences, Faculty of Medicine and Health Sciences, Stellenbosch University, Cape Town 7550, South Africa

3 Division of Orthopaedic Surgery, Department of Surgical Sciences, Faculty of Medicine and Health Sciences, Stellenbosch University, Cape Town 7550, South Africa

4 Department of Anatomy, School of Medicine, University of Namibia, Windhoek, Namibia 10026

The COVID-19 infection caused by the SARS-CoV-2 coronavirus, declared a pandemic by the World Health Organisation (WHO) on 11 March 2020, has necessitated distance learning by higher education institutions around the world [1]. With the implementation of lockdown in South Africa on 26 March 2020, lifted in gradual stages as from 1 May 2020 , the challenge has been to deliver teaching in a format that will allow the accomplishment of learning objectives and not compromise student learning.

At the author's institution, the decision was made to complete the academic year's content in an online format, as it was unclear as to when students would be allowed to return to campus. Lecture content was placed on the virtual learning management platform, Moodle (Moodle HQ, West Perth, Australia), with detailed instructions to guide learning in an asynchronous fashion. In most modules, chat rooms and 
forums were live during the scheduled lecture slots for students to interact with the lecturers and one another.

However, this approach was not considered optimal for the continuation of the Clinical Anatomy journal club during the lockdown period. The journal club (JC) is compulsory for the Bachelor of Science Honours (BScHons) in Anatomy students and is facilitated by two lecturers in the Division, who took over in January 2020. The journal club meets every second Friday at noon for $1 \mathrm{~h}$ to discuss scientific writing and/or a particular topic in Anatomy. Two articles regarding the topic are prescribed by the facilitator 2 weeks before the session. During the session, students are prompted towards active discussion on the topic and the circulated articles with the facilitation of the lecturers. The learning outcomes of the Clinical Anatomy journal club are for students to improve scientific communication skills, critically appraise research articles, and become familiar with and create a library of the relevant literature in anatomical research (adapted from Musits and Mannix [2]). Therefore, an online JC that facilitated these outcomes by allowing synchronous contact between the members was considered appropriate.

Journal clubs have a long history in the health sciences since their inception by Sir William Osler in 1875 in Canada [3]. Generally, it involves a group of individuals in a particular field meeting on a regular basis to discuss research articles [4]. Journal clubs are particularly beneficial in resident training and postgraduate programmes as they facilitate the development of critical appraisal skills [4, 5], understanding of statistics $[4,6]$, regular reading of the literature $[4$, 7], and promote the integration of article results into practice (Pearce-Smith, 2006, cited in Fricker and Roper [5]). Although journal clubs were initially developed for busy clinicians to keep up to date with literature, they have also become popular in other fields such as biology [8], library sciences (Pearce-Smith, 2006, cited in Fricker and Roper [5]), health sciences education [9], and biomedical sciences [10]. Although the format varies between institutions, the traditional format involves presentation of a journal article by one person, followed by a group discussion [11].

Online JCs have increased in popularity in medicine over the last decade as they allow members to participate from wherever they are physically situated $[12,13]$. These meetings can be synchronous (for example a conference call) or asynchronous (a social media thread or forum discussion) [13]. For synchronous meetings, any webinar programme can be used that allows concurrent chat, audio-visual streaming, and screen sharing [2]. Asynchronous JCs are popular in busy specialties where it is difficult to schedule either a physical session or a synchronous online session due to the availability of members [14]. This allows all members to be involved in the discussion despite their geographical location or schedule. The readings are provided in advance, and a facilitated discussion is held over a predefined period.
The discussion thread can be archived, allowing future reference and dissemination [13]. Twitter ${ }^{\mathrm{TM}}$ (Twitter, Inc., San Francisco, CA) is the most commonly used social media medium for asynchronous journal clubs [13, 15] although WhatsApp ${ }^{\mathrm{TM}}$ (Facebook, Inc., Menlo Park, CA) was used successfully in a busy orthopaedic department in 2019 [14].

Regardless of the format, virtual journal clubs (VJC) bridge geographical barriers as members can participate from anywhere in the world [13]. Experts or even the authors of articles can be invited to participate in the session [7, 12], increasing networking opportunities [2, 7] and promoting interdisciplinary collaboration [13].

There are no published reports on the theme of online journal clubs in anatomy; however, online journal clubs are in existence for many clinical specialties, as well as nursing, and health science education. The experience of students having to suddenly adapt to a new format of the JC under extraordinary circumstances, such as the COVID-19 pandemic, is not known. Thus, the aim was to develop, implement, and appraise a synchronous virtual journal club for Clinical Anatomy during the COVID-19 South African lockdown. In support of the aim, the objectives were to explore the perceptions of $\mathrm{BScHons}$ students on transitioning to a virtual journal club during the COVID-19 pandemic and on the relevance of the content.

\section{Materials and Methods}

A qualitative exploratory study design within an interpretive/constructivist paradigm was followed with the aim to explore students' perceptions of a virtual anatomy journal club during the COVID-19 South African lockdown. The study is specific to the context of the author's division and institution, focusing on the group of five BScHons students. This approach was used to explore and yield perceptions that are likely to inform evidence-based online anatomy journal clubs. The sample size was too small to do a quantitative survey such as a Likert scale; therefore, a qualitative questionnaire was used as the data collection instrument. An openended questionnaire was selected as it is a standardized, anonymous, and fast way to gather information. Interviews were not considered suitable as none of the investigators are proficient in interview technique, little time was available for training, and the lockdown also limited the availability of suitable training. It was also important to avoid interviewer bias, as the investigators facilitate and assess the JC.

Members of the Clinical Anatomy journal club were approached during the recess of April 2020 to ascertain their preference for the format of continuing journal club. Members were asked about the quality of their internet connection and availability of electronic devices and software. Given the prospects of having no face-to-face 
contact for at least a few months, a combination of synchronous and asynchronous platforms was decided upon.

Consequently, Microsoft Teams ${ }^{\mathrm{TM}}$ (Microsoft Corp., Redmond, WA) was selected as all members had access via the institutional subscription on their devices, as well as a reliable internet connection. A video explaining how to join a Teams meeting was emailed to all members. Ground rules were communicated to all members in advance and agreed upon at the start of the first meeting. The meeting time was retained as every second Friday at noon, with the duration of $1 \mathrm{~h}$. The articles were distributed to the group 2 weeks in advance along with critical appraisal tools such as the Anatomical Quality Assessment (AQUA) Tool [16], the AQUA Checklist [17], or a customized list of questions designed by the JC coordinator for certain topics, intended to guide students' reading and reflection, and to stimulate discussion. The AQUA Tool was designed to assess the quality of original anatomical studies intended for inclusion in systematic reviews and meta-analyses [16]. This tool assesses the risk of bias by answering yes, no, or unclear to questions in five domains, namely the objectives of the study and study characteristics, study design, methodology, descriptive anatomy, and the reporting of results. Depending on the predominant option selected, the risk of bias can be estimated as low, high, or unclear for each domain. This information assists with critically appraising articles and determining the reliability of their findings [16]. The AQUA Checklist is a set of guidelines for the inclusion of information in anatomical publications and is also useful for reviewing articles [17]. The Checklist aims to improve the standards of original anatomical study reports and contains 29 items that should be included in every manuscript under the following sections: title, abstract, introduction, methodology, results, discussion, conclusions, and other information [17].

A WhatsApp group was set up for the group to continue the discussion for a maximum of 1 week after the live meeting as well as to provide a summary at the close of the discussion. WhatsApp was selected as all were regular users and the postgraduate members were already in a group for communication related to their studies. The Moodle page was used as the homepage for instructions and other communication related to JC.

The five BScHons students were invited to participate via Moodle as they are compulsory members of the journal club. The sampling strategy for this study was thus a convenience one, namely all participating students.

A questionnaire (Supplement I) was developed to obtain information from the $\mathrm{JC}$ members relating to their experience with the virtual journal club. A total of 21 questions centred on students' experiences of the VJC and the content discussed in both face-to-face and online sessions. Questions were a combination of yes/no and free text. The questionnaire was pilot tested with the postgraduate Masters in Anatomy students.

The questionnaire was administered via the Moodle page for the BScHons students. Informed consent was obtained before students were able to proceed with the questionnaire (Supplement II). The questionnaires were entirely anonymous, and no demographic information was collected. On Moodle, anonymity was obtained by selecting the "anonymous" option when setting up the questionnaire. Thus, no identifying information such as name or email addresses was linked to the questionnaire.

The questionnaires were available on Moodle for 2 weeks until 31 July 2020. After the submission date, completed questionnaires were downloaded to the researcher's password protected computer.

Responses were analysed by thematic analysis by following the six-phase process developed by Braun and Clarke [18]. After initially reading through the responses, codes were manually developed for relevant comments by three of the researchers, one of whom has experience with qualitative research. Any discrepancies in coding were resolved between the researchers. Themes were generated from the codes and reviewed by the whole research team. Themes were then defined and named, and the final phase ("report production") was done by the whole team. The process was iterative. Three of the five members of the research team have experience with qualitative research, while the other two were undergoing training at the time of the research.

The four criteria to consider ensuring trustworthiness in qualitative research are credibility, dependability, confirmability, and transferability [19, 20]. Credibility was ensured by debriefing and triangulation, whereby members of the team independently coded and categorized the data into themes, which were discussed on a regular basis. Transferability was ensured by providing information on the context of the study and a rich and detailed description of the data. To guarantee dependability, detailed information on the methodology is provided and the questionnaire is available as a supplement. Confirmability was ensured by recording data truly and systematically, examining transcripts for accuracy, continuously re-examining data, being flexible, and open towards process and ideas and peer debriefing $[19,20]$.

Ethical approval was obtained from the Health Research Ethics Committee (N20/05/056), and institutional permission was obtained before questionnaires were sent to members. Informed consent was obtained by participants clicking "yes" before being able to proceed with the questionnaire. Participation in JC is compulsory as it is part of the curriculum; however, participation in the survey was voluntary, with no incentives provided for participating.

Two of the researchers were directly involved in the JC, and two researchers were not involved but part of the same division. One researcher, not affiliated with the institution, 
served as an external member during thematic analysis to minimize any bias. Further possible bias during data analysis was minimized through peer debriefing amongst the researchers as mentioned previously.

\section{Results}

Three out of five enrolled BScHons students responded to the invitation. Two main themes emerged during the analysis. The first related to the virtual format of the JC, and the second focused on the content and topics covered during the JC sessions (see Table 1).

\section{Virtual Format}

Several elements in the online environment during the JC session appeared. The subthemes of the virtual format were challenges encountered in communication, connectivity issues in the online space, and the experience of participants of the JC. A participant remarked that "It is also difficult since two people often start speaking at the same time and then you feel you interrupt each other". Regarding connectivity, a student noted that "on occasion, the network would lag or dip and therefore may miss out on information, which is less likely to happen in an in-person discussion. Luckily, this did not happen often, and I do not feel I have missed anything major from the sessions." Students' experience of the virtual JC necessitated adaptation as demonstrated by the comment of one participant: "help me learn how to adapt from normal in-person discussions to a more virtual method, while still being able to obtain the same result." Several students found the WhatsApp group beneficial, and one remarked that: "I do enjoy the WhatsApp group, posting current and relevant articles etc. It makes communication and sharing of information much easier. It also promotes the integration of the knowledge from JC into daily life, and critically analyzing the information around us, since it may be relevant to share with others on the group."

Table 1 Themes and subthemes emerging from the study

\begin{tabular}{ll}
\hline Theme & Subtheme \\
\hline Virtual format & Challenges in communication \\
& Connectivity \\
& Experience (incl WhatsApp group) \\
Content & Knowledge (new and implementation) \\
& Value \\
& Time (prep, duration, timetabling)
\end{tabular}

\section{Content}

The content/topics covered during the virtual JC helped students with the acquisition and implementation of knowledge. The subthemes of the content pertained to acquisition of new knowledge and the implementation thereof, as well as time. Statements such as "I also think that as JC progressed, I incorporated what I learned in each session in my thesis" and "It's as if JC teaches one to be 'street smart' in the academic world" supports this. The time subtheme covered numerous aspects. These include time spent on preparation for the virtual JC, the duration of the session, and timetabling the JC into the overall BScHons programme. Some comments relating are "I appreciate that JC does not take too much time to prepare for and is not too often since we do have a lot on our plates." The duration of the JC was determined also by the topic and degree of participation and engagement: "Yes, the discussion length was usually dictated by how much there was to discuss on a topic. I would rather be introduced to a range of topics that I can then go and independently research more on, rather than spend too long on one."

\section{Discussion}

Journal club is a signature pedagogy of the Sciences [21]. The learning outcomes of a JC concentrate around improvement of scientific communication, reading, and critical appraisal of published literature. It also creates familiarity with current literature and topics of debate. To the best of the authors' knowledge, there are no published reports describing journal clubs in the anatomical sciences. Journal clubs, when viewed through the theoretical lenses of social learning, promote learning through a community of practice, and enable distributed leadership [22]. Community of practice theory describes a group of people who interact regularly and build social relationships based on a shared interest in a particular domain and develop a set of resources which facilitate learning within that domain [23]. Community of practice is applied in many fields including higher education and health professions education [24]. Furthermore, the establishment of such a community of practice allows collaborative learning through contact between staff and students, and facilitates support, guidance and collaboration, the creation of meaning and increased access to knowledge and practices with accountability between members [25]. The three criteria posited by Koliba and Gajda [24] for determining the formation of a community of practice are the presence of a group of individuals with shared interests, a physical or online space in which the individuals interact on a regular basis, and the common domain or practice. Within our context, all three criteria were present, revealing that a 
community of practice was formed within the virtual journal club. The comment of one student provides further support for this claim: “... It also promotes the integration of the knowledge from JC into daily life, and critically analyzing the information around us, since it may be relevant to share with others on the group."

Two themes arose from the data: the virtual format and the content covered in the journal club. After initial adjustment to the online environment, it emerged that all students enjoyed the sessions and suggested continuing in a hybrid format after lockdown. A further advantage was the convenience of participating from the home environment. Students perceived the content as relevant and could apply skills obtained to their research. Topics were selected by the staff according to their relevance to junior researchers in anatomy. These included scientific writing (namely proposal, literature review, methodology, title and abstract, results and discussion), the principles of evidence-based anatomy, and using social categories as variables in biological research. Aspects associated with publication ethics, such as predatory publishing, authorship, salami publishing, and the peer review process, statistics, critical appraisal tools, and a session on understanding systematic reviews and meta-analyses, were also discussed (Table 2). While the discussions focused on quantitative research, as most students were researching in this paradigm, qualitative and mixed method paradigms were also acknowledged. As Al-Imari et al. [26] also reported, students value content that is relevant. What emerged from this present study was the value of the hidden curriculum as reflected in participant 2's comment: "I was exposed to a variety of new topics that I was not even aware of, so all were very useful!" These are the topics that relate to publication ethics, social categories in anatomical research and evidence-based anatomy.

Virtual journal clubs are well known and well received in many clinical specialties. They bridge geographical barriers and encourage national and international attendance $[13,27]$. Prior to lockdown they were frequently utilized in clinical medicine due to time constraints and varying rosters [28]. This was especially useful on asynchronous mediums such as Twitter [13, 14]. However, for small groups, faceto-face discussions are still preferred when possible [26].

The international lockdown with required social distancing measures fast-tracked digital transformation on a global scale [27]. Overall, our students experienced this positively and it seems to have led to improved learning effectiveness in them and others [27].

Several studies report on their experiences with virtual journal clubs during the pandemic. Slanetz et al. [28] reported positively on four radiological journal clubs that transitioned to a virtual format. Multilevel learning was achieved with attendees reporting an increase in knowledge and communication skills. Similarly, Aulakh et al. [29] described learning as being more effective in the virtual JC than in face-to-face sessions and encouraged a hybrid design post-pandemic.

Any conferencing software that allows screen sharing can be used. In the present study, Microsoft Teams was selected as all participants had access via the university subscription.
Table 2 Virtual journal club timetable and topics

\begin{tabular}{ll}
\hline Date & Topic \\
\hline 31 January* & Welcome \\
14 February* & Proposal writing \\
3 March* & Scientific writing-Introduction/Literature Review \\
13 March* & Evidence-based anatomy \\
10 April & Scientific writing-Methods \\
24 April & Good Friday-No JC \\
8 May & The use of race as a variable in research \\
22 May & Scientific writing-Title and abstract, abstract writing assignment \\
& Feedback on abstracts \\
5 June & Predatory journals and conferences \\
19 June & Salami publishing, critical appraisal assignment \\
10 July & Feedback on critical appraisal assignment \\
24 July & Authorship and peer review process \\
7 August & Scientific writing-Results \\
21 August & Scientific writing-Discussion, discussion writing assignment \\
4 September & Feedback on discussion writing assignment \\
18 September & Statistics \\
\hline
\end{tabular}

*Face-to-face sessions 
Other virtual journal clubs use a variety of software, including Microsoft Teams [27] and Zoom ${ }^{\mathrm{TM}}$ (Zoom Video Communications, Inc, San Jose, CA)[28].

While Twitter is a popular asynchronous platform for virtual journal clubs [30], few publications report the use of WhatsApp [14, 31]. WhatsApp was selected for this VJC as all students and staff were already regular users, while not all of them utilized Twitter. In addition, WhatsApp was considered more private than Twitter, where posts could be potentially seen by non-members, depending on individual's privacy settings. Studies have shown students are uncomfortable with expressing professional opinions in a public space such as social media [26], falling outside of the community of practice of a protected and supportive environment. Twitter-based journal clubs are more appropriate where a large audience is desired to provide networking opportunities and to stimulate a wider discussion [30]. In Al-Imari 's study, many students did not use Twitter, and these authors suggest that using a tool that is familiar may contribute to the success of a programme [26]. Robertson et al. [32] also found that all journal club participants were regular users of WhatsApp and thus used this tool for asynchronous discussion.

The virtual JC provided social interaction with many reporting enjoyment of the sessions [28, 33]. In addition, senior researchers may be invited to attend, such as an expert in the topic or the authors of the reviewed article [28]. This extends the community of practice and provides an invaluable opportunity for junior researchers to interact with wellknown authors. There were some disadvantages encountered as well. The major features were a lack of non-verbal communication during sessions, some technological problems, and distractions in the home environment [26, 27]. Participants in a hybrid journal club report that the use of conferencing software divided attention and thus hindered discussion [26]. Technological challenges can be overcome by two facilitators hosting the session, where the second one is able to take over in case of lost connectivity [28]. The participation and inclusion of all members can be encouraged by the facilitator asking questions and ensuring an equal opportunity for contribution.

"Netiquette" in the form of ground rules may facilitate improved communication. For example, muting oneself after speaking will signal that it is another person's turn to speak and thereby reduce the potential for interruption. Muting may also reduce interrupting another speaker as one has to actively unmute their microphone on the virtual platform to be heard. Participants may, however, utilize the typed chat function while another is speaking, and most platforms have a "raise hand" function that is used to indicate when one wishes to contribute. Use of the video camera will facilitate non-verbal communication cues where this is possible. In the present study, ground rules were agreed upon before the first virtual session, as was the practice in other virtual journal clubs (28). However, the video camera was not used to save on data costs and to ensure a good connection.

Our study faced several limitations. The small BScHons class of 2020 yielded a small sample size. The emergency transition to remote teaching required rapid development and implementation of curricula; however, the recess provided time for the facilitators to design the virtual JC and the content was not changed. Furthermore, the use of interviews may have led to richer data especially in the small sample size. As this was the first year that the investigators ran the journal club, there is no data from previous years with which to compare the experiences of the students. This project is currently being expanded by conducting interviews with the 2021 cohort.

Based on the experience with the rapid transition to a virtual journal club, the following practical recommendations are suggested:

- Utilize software and resources that are readily available, for example through institutional subscription, preferably with some degree of familiarity for all members of the team.

- Consider using more than one communication platform as it allows communication during unforeseen circumstances, for example unexpected loss of internet connectivity or device malfunction.

- Discuss and agree on ground rules in the first session and distribute a copy to each member.

- Consider the type of internet connection and data availability of all members when deciding whether video streaming will be used.

- Two facilitators allow for division of duties, for example one facilitating content while the other attending to any technical problems.

\section{Conclusion}

The virtual journal club facilitated continued interaction between the postgraduate anatomy students and the academic personnel, fostering a community of practice during the COVID-19 pandemic. Staff and students were flexible and adapted rapidly to the virtual JC. Teaching and learning benefits were maintained and allowed the learning outcomes to be reached. The journal club will continue in a hybrid format (face-to-face and virtual) after lockdown with the intention of inviting guest speakers and attendees. As there are no published reports of anatomy themed online journal clubs, it is expected that other institutions considering implementing virtual Anatomy JCs will benefit from the results of this study. 
Supplementary Information The online version contains supplementary material available at https://doi.org/10.1007/s40670-021-01325-8.

Acknowledgements The authors would like to acknowledge the students who participated in the virtual journal club.

Author Contribution All authors contributed to the study conception and design. Material preparation, data collection, and analysis were done by all authors. The first draft was written by Kerri Keet with all authors revising subsequent drafts. All authors read and approved the final manuscript.

Data Availability Available from authors.

\section{Declarations}

Ethics Approval N20/05/056 and institutional approval.

Consent to Participate Obtained before participants could proceed with the online questionnaire (By clicking "yes" START SURVEY you are confirming that you are over 18 years old and have read and understood the above explanation about the study, and that you agree to participate. You also understand that your participation in this study is strictly voluntary.) Individual consent to publish was not obtained as it would compromise anonymity of the participants; however, participants were informed that results will be disseminated through presentation at conferences and publication.

Conflict of Interest Two authors are involved with conducting the virtual journal club.

\section{References}

1. Longhurst GJ, Stone DM, Dulohery K, Scully D, Campbell T, Smith CF. Strength, Weakness, Opportunity, Threat (SWOT) Analysis of the adaptations to anatomical education in the United Kingdom and Republic of Ireland in Response to the COIVD-19 Pandemic. Anat Sci Educ [Internet]. 2020 Apr 19; Available from: http://www.ncbi.nlm.nih.gov/pubmed/32306550

2. Musits AN, Mannix AL. Synchronous online journal club to connect subspecialty trainees across geographic barriers. West $\mathbf{J}$ Emerg Med. 2020;21(1):33-6.

3. Linzer M. The journal club and medical education: over one hundred years of unrecorded history. Postgrad Med J. 1987;63(740):475-8.

4. Deenadayalan Y, Grimmer-Somers K, Prior M, Kumar S. How to run an effective journal club: a systematic review. J Eval Clin Pract [Internet]. 2008 Oct 1 [cited 2020 Apr 16];14(5):898-911. Available from: https://doi.org/10.1111/j.1365-2753.2008. 01050.x

5. Fricker A, Roper T. An open invitation to join HILJ [Journal] Club. Health Info Libr J. 2019;36(4):295-8.

6. Touchet BK, Coon KA, Walker A. Journal Club 2.0: Using teambased learning and online collaboration to engage learners. Acad Psychiatry [Internet]. 2013 Nov [cited 2020 Apr 15];37(6):442-3. Available from: http://www.ncbi.nlm.nih.gov/pubmed/24185298

7. Sortedahl C. Effect of online journal club on evidence-based practice knowledge, intent, and utilization in school nurses. Worldviews Evidence-Based Nurs. 2012;9(2):117-25.

8. Brill G, Falk H, Yarden A. Teachers' journal club: bridging between the dynamics of biological discoveries and biology teachers. J Biol Educ. 2003;37(4):168-70.
9. McLeod P, Steinert Y, Boudreau D, Snell L, Wiseman J. Twelve tips for conducting a medical education journal club. Med Teach. 2010;32(5):368-70.

10. Mcdonough V. Improving journal club: increasing student discussion and understanding of primary literature in molecular biology through the use of dialectical notes. Biochem Mol Biol Educ. 2012;40(5):330-2.

11. Hartzell JD, Veerappan GR, Posley K, Shumway NM, Durning SJ. Resident run journal club: a model based on the adult learning theory. Med Teach. 2009;31(4):156-61.

12. Chetlen AL, Dell CM, Solberg AO, Otero HJ, Burton KR, Heller MT, et al. Another time, another space: the evolution of the virtual journal club [Internet]. Vol. 24, Academic Radiology. Elsevier USA; 2017 [cited 2020 Apr 15]. p. 273-85. Available from: http://www.ncbi.nlm.nih.gov/pubmed/28193377

13. Friedman KA, Herman SW, Fornari A. Medical education using minimal technology: achieving professional development. Med Educ Online [Internet]. 2019;24(1). Available from: https://doi. org/10.1080/10872981.2019.1622365

14. Clesham K, Piggott RP, Sheehan E. A prospective review of a novel electronic journal club format in an orthopedic residency unit. J Surg Educ. 2020;77(1):115-23.

15. Roberts MJ, Perera M, Lawrentschuk N, Romanic D, Papa N, Bolton D. Globalization of continuing professional development by journal clubs via microblogging: a systematic review. J Med. 2015;17(4).

16. Henry BM, Tomaszewski KA, Ramakrishnan PK, Roy J, Vikse J, Loukas M, et al. Development of the Anatomical Quality Assessment (AQUA) Tool for the quality assessment of anatomical studies included in meta-analyses and systematic reviews. Clin Anat [Internet]. 2017 Jan [cited 2018 Sep 8];30(1):6-13. Available from: https://doi.org/10.1002/ca.22799

17. Tomaszewski KA, Henry BM, Kumar Ramakrishnan P, Roy J, Vikse J, Loukas M, et al. Development of the Anatomical Quality Assurance (AQUA) checklist: guidelines for reporting original anatomical studies. Clin Anat. 2016;30(1):14-20.

18. Braun V, Clarke V. Using thematic analysis in psychology. Qual Res Psychol. 2006;3:77-101.

19. Frambach JM, van der Vleuten CPM, Durning SJ. AM last page. Quality criteria in qualitative and quantitative research. Acad Med. 2013;88(4):552.

20. Shenton AK. Strategies for ensuring trustworthiness in qualitative research projects. Educ Inf. 2004;22(2):63-75.

21. Bowers AJ, Murakami-Ramalho E. The research journal club: pedagogy of research in the preparation of students in educational leadership. J Res Leadersh Educ. 2010;5(10):335-56.

22. McGlacken-Byrne SM, O'Rahelly M, Cantillon P, Allen NM. Journal club: old tricks and fresh approaches. Arch Dis Child Educ Pract Ed. 2020;105(4):236-41.

23. Wenger E. Communities of practice: a brief introduction [Internet]. National Science Foundation (U.S.); 2011 [cited 2021 May 14]. Available from: https://scholarsbank.uoregon.edu/xmlui/ handle/1794/11736

24. Koliba C, Gajda R. "Communities of practice" as an analytical construct: Implications for theory and practice. Int J Public Adm. 2009;32(2):97-135.

25. Pallas AM. Preparing education doctoral students for epistemological diversity. Educ Res. 2001;30(5):1-6.

26. Al-Imari L, Nutik M, Rozmovits L, Alvi R, Freeman R. Family medicine journal club: to tweet or not to tweet? Fam Med. 2020;52(2):127-30.

27. Aulakh GS, Duggal S, Sutton D. Findings from an OMFS journal club: is COVID-19 the catalyst we have needed to embrace technology? Br J Oral Maxillofac Surg [Internet]. 2020;6-11. Available from: https://doi.org/10.1016/j.bjoms.2020.08.056 
28. Slanetz PJ, Bedi H, Kesler T, Chetlen A. Optimizing journal clubs in the post-coronavirus disease 2019 (COVID-19) Era. J Am Coll Radiol [Internet]. 2020;2019:2019-21. Available from: https://doi. org/10.1016/j.jacr.2020.07.031

29. Aulakh GS, Duggal S, Sutton D. Findings from an OMFS journal club: is COVID-19 the catalyst we have needed to embrace technology? Br J Oral Maxillofac Surg [Internet]. 2020 [cited $2021 \mathrm{Feb} 1$ ]; Available from: https://pubmed.ncbi.nlm.nih.gov/ 33071050/

30. Stoneman S, Hiremath S. Twitter-based journal clubs: bringing critical appraisal to the social table. Semin Nephrol [Internet]. 2020;40(3):264-72. Available from: https://doi.org/10.1016/j. semnephrol.2020.04.004
31. Wilmshurst S, Railton K. A smart (phone) solution for journal club. In: Great Ormond Street Hospital Conference 2018: Continuous Care. 2018. p. A2.1-A2.

32. Robertson C, Tong G, Chee LC. Experiences of continuing medical education during COVID 19. 2020;3-5. Available from: https://doi.org/10.22541/au.159413055.59419985

33. Hughes K, Redfield R, Vojnika J, Mallozzi M, Jones RB, Aoun R, et al. Response to rapidly changing healthcare information regarding COVID-19 with virtual journal club. In: House Staff Quality Improvement and Patient Safety Conference. 2020.

Publisher's Note Springer Nature remains neutral with regard to jurisdictional claims in published maps and institutional affiliations. 